\title{
Immunopathological aspects of coronavirus infections
}

\author{
Helmut Wege \\ Institute for Diagnostic Virology, Federal Research Centre for Virus Diseases of Animals, \\ Friedrich-Loeffer-Institutes, D-17498 Insel Riems, Germany
}

\section{Introduction}

Coronaviruses are widespread pathogens that cause a number of important diseases in mammalian and avian species. Their pathogenic potential ranges from respiratory and gastrointestinal diseases to hepatitis, encephalomyelitis, vasculitis and coagulopathies. The following diseases are of major economical importance: transmissible gastroenteritis and porcine respiratory coronavirus infections in pigs, diarrhea in calves, infectious bronchitis in chickens, feline infectious peritonitis in cats $[8,100]$. About $30 \%$ of common colds in human beings are attributed to these viruses. Furthermore, they cause a broad range of diseases in mice and rats. The majority of coronaviruses induce acute, self-limiting diseases. The major exceptions are infections caused by feline and murine coronaviruses. Feline infectious peritonitis (FIP) represents a debilitating condition based on infection of the monocyte/macrophage lineage and is associated with immune-mediated damage $[20,65,71]$. Murine coronaviruses (mouse hepatitis virus, MHV) can spread inapparently or may hide as persistent infections that modulate the immune response $[38,100]$. Therefore, MHV infections may severely impair results of experimental studies and are of major concern in livestock breeding. On the other hand, these infections are interesting for analysing disease processes. MHV-JHM and MHV-A59 are mainly employed for studies of virus-induced demyelination in the central nervous system, whereas MHV-3 is a versatile model for the study of diseases of the liver and the lymphoreticular system. These aspects constitute the major focus of the following sections.

\section{Structure and replication of coronaviruses}

Typical coronaviruses are pleomorphic to rounded particles with a lipid envelope surrounded by a fringe of surface projections termed spikes or peplomers $[8,42,87]$. Their genome consists of a large, single-stranded RNA molecule comprising about 28-32 kilobases of nucleotides. This is the largest known RNA genome. The RNA is 
of positive polarity, with a cap structure at the $5^{\prime}$ end and polyadenyl sequences at the $3^{\prime}$ end. The $5^{\prime}$ end codes for the polymerase, followed by genes for envelope proteins and the nucleocapsid protein. Expression of the coronavirus genome involves a series of subgenomic mRNA, each containing one or more open reading frames. In the case of structural proteins, only the $5^{\prime}$ end of the gene is translated. A similar gene organisation and expression strategy is employed by arteriviruses (e.g. equine arteritis virus) and toroviruses (e.g. Berne virus). Therefore, despite considerable morphological differences, these families may derive from a common ancestor of the "coronavirus-like superfamily" [85]. They each have a similar polymerase unit coupled to different sets of structural genes (modular evolution). About two thirds of the genome is required to code for the polymerase functions, corresponding to about 800 kilodaltons of amino acids.

The genomic RNA and the nucleocapsid protein $\mathrm{N}$ form a helical structure, which is surrounded by a lipid bilayer. Attached to $N$ is the matrix glycoprotein $\mathbf{M}$, which protrudes into the lipid envelope. The major surface glycoprotein is the spike protein $\mathrm{S}$. This protein is important for cell fusion, attachment to receptors on the cell surface and induction of protective immunity. The $S$ gene displays a considerable genetic heterogeneity involving mutations, deletions and recombination events, which has a strong impact on virulence and tissue tropism. The virus receptors on the cell surface mirror this heterogeneity. Murine coronaviruses employ carcinoembryonic antigens as receptors; these are related to the IgG superfamily and consist of a large number of variants expressed in different tissues [19]. Other coronaviruses, such as the porcine transmissible gastroenteritis virus or the human coronavirus $229 \mathrm{E}$, bind to a completely different type of molecule, the aminopeptidases [14].

A further surface glycoprotein, the haemagglutinin esterase (HE), is not expressed by all coronaviruses. This protein promotes binding to neuraminic acid and functions as a second receptor system. Depending on the coronavirus strain, the haemagglutinating activity is either associated with $\mathrm{HE}$ or can be a property of the $\mathrm{S}$ protein [8, 871.

\section{Immunopathology of feline coronavirus infections}

In several virus diseases such as Dengue haemorrhagic fever, yellow fever or some stages of HIV infections, a cytokine-mediated dysregulation of the immune system results in an augmentation of pathology by the antibody response through deposition of immune complexes or antibody-mediated enhancement of infectivity $[31,53,104]$. Chronic inflammations elicited by feline coronavirus infections provide an interesting virus-host system in which such mechanisms can be studied.

\section{General biological and clinical aspects}

Feline coronaviruses comprise multiple strains or biotypes that differ in their pathogenic potential and organ tropism [65,71]. The feline infectious peritonitis virus (FIPV) strains have probably evolved from feline enteric coronaviruses (FECV) by mutations or recombination events $[20,73]$. FECV causes rather inapparent infections and can induce mild enteritis in kittens. By contrast, FIPV induces an array of clinical diseases with high mortality, which are characterised by inflammatory changes in 
many organ systems $[71,89]$. The disease is predominant in young cats (of less than 1 year of age). It is debatable whether the greater incidence among purebred cats is the result of a certain genetic predisposition or a management problem of catteries. The disease is transmitted by contact (ingestion, inhalation, bites) and shed via feces and secretions. The manifestation of clinical disease occurs after an incubation period of a few weeks to months and years. Asymptomatic carriers may be involved. Two different manifestations can be diagnosed, either an effusive (wet) form or a non-effusive (dry) form [71, 72]. Furthermore, combinations of these phenotypes complicate the clinical definition of FIP.

Characteristic of the effusive form is a fibrin-rich fluid accumulating in the peritoneal, pericardial or renal, subcapsular spaces. The severity and type of signs depends on the site of effusion, in most classical cases the cats develop an enlargement of the abdomen. General symptoms are anorexia, weight loss, dehydration, deafness and fever. Depending on the site of inflammation, liver functions or the pancreas can be involved. The disease process leads, within weeks to months, to the death of the animal.

In the effusive form multiple granulomas can affect different organ systems. Neurological signs such as paresis, ataxia, behavioural changes and seizures are often observed. These clinical signs can fluctuate in phases over many months.

Infection by the oronasal route is followed by replication in the pharyngeal, respiratory or intestinal epithelial cells. Monocytes are the predominant target, whereby the viremic phase remains predominantly cell associated $[105,106]$. In the next step, virus spreads to the macrophages of the reticuloendothelial organs or into perivascular areas. This results in necrotising pyogranulomas with phlebitis and thrombosis.

\section{Antibody-dependent enhancement of infectivity}

The most puzzling phenomenon observed during FIP is the acceleration of disease if seropositive cats are challenged with FIPV. This more fulminant accelerated FIP is primarily associated with the existence of serum antibodies. Experimental transmission of immune serum or purified anti-FIPV IgG to seronegative kittens before challenge also resulted in an acceleration of disease [72, 104-106].

Two major mechanisms promote and drive the pathological changes. The first mechanism involves immune complexes consisting of antibodies, complement $\left(C^{\prime}\right)$ and FIPV proteins $[29,31,32]$. Activation of $C^{\prime}$ appears to be the major factor eliciting inflammations and the blood-coagulation cascade [107]. Under experimental conditions, subclinical disseminated intravascular coagulation (DIC) can be elicited and the inflammations are associated with an array of mediators such as interleukin (IL)-1, IL-6, leukotriene B4 or prostaglandin E2. The second mechanism is triggered by antibodies that enhance the infection instead of blocking or neutralising the virus. Such an antibody-dependent enhancement (ADE) can be emulated by experiments with macrophages in vitro [27]. The detailed mechanism of $A D E$ appears to be quite variable. Basically, the efficiency of infection of monocytes or macrophages is much higher with virus-antibody complexes than with virus alone $[66,67]$. This phenomenon involves a receptor-mediated endocytosis employing $\mathrm{Fc}$ receptors or $\mathrm{C}^{\prime}$ receptors and CD4 receptors. It is not yet clear whether Fc receptor-mediated enhancement of FIP infections occurs in absence or presence of $\mathbf{C}^{\prime}$. 
The viral structures that are involved in the induction of enhancing antibodies have been defined in more detail [66-68]. In the case of FIPV, certain epitopes on the $S$ protein are associated with this phenomenon, whereby the same epitope can mediate virus neutralisation by binding of antibodies in a dose-dependent manner [10]. A smaller amount of antibodies is required for a maximal enhancement effect than for neutralisation. Furthermore, antibodies binding to the matrix protein $M$ can also result in an enhancement. In addition, the IgG subclass plays a role. Whereas IgG 2a-specific monoclonal antibodies $(\mathrm{mAb})$ can be responsible for either enhancement or neutralisation, IgG $1 \mathrm{mAb}$ are strictly associated with neutralisation. The enhancing antibody may promote the infection by targeting the virus to the surface of cells bearing Fc receptors for IgG, thus resulting in phagocytosis or a more intense interaction of the virus proteins with the specific receptor on the cell surface. However, experiments were presented which demonstrate a correlation between the number of infected macrophages and the presence of enhancing antibodies. It was also speculated that the enhancing antibodies promote the uncoating of virus within the cell.

The implications for ADE in vaccination strategies are obvious. Trials to protect cats by vaccination with recombinant vaccinia virus expressing the FIPV $S$ protein were, however, a failure. Challenge of vaccinated cats displaying $S$-specific antibodies resulted in a significantly accelerated infectious peritonitis instead of protection [96]. Furthermore, depending on the challenge schedule, a correlation between accelerated FIP and enhancing antibodies in the serum was demonstrated. By contrast, no such acceleration was encountered if cats were vaccinated with recombinants expressing either $\mathbf{N}$ or $\mathbf{M}$ protein of FIPV.

\section{Murine coronavirus infections as a model for virus-induced demyelination}

Many diseases of the central nervous system (CNS) are accompanied by inflammatory demyelination. Diseases such as visna in sheep, canine distemper in dogs or a number of parainfectious encephalomyelitides in humans are typical examples [16]. Furthermore, an involvement of virus infections in multiple sclerosis (MS) is a widely discussed and attractive hypothesis. This enigmatic disease process is driven by a combination of immunological, genetic and environmental factors [46, 69]. Coronavirus infections in mice and rats have been employed as a model to analyse such pathogenic mechanisms.

The murine coronaviruses (or MHV) comprise a large number of strains and biotypes [8, 38, 100]. Most studies have been performed with MHV-JHM and MHVA59 in rats and mice. The outcome of infection depends on the properties of the virus, route of inoculation and host factors such as genetics, age and immune status. Mice are in general more susceptible and a variety of organ systems can be involved. Rats must be infected intracerebrally, but the virus remains more restricted to the CNS. The major target cells in the CNS are neurons and oligodendroglia, whereas during persistent infection the astrocytes are the sites of predilection which harbour and spread the virus [92].

In both mice and rats, the immune response has a marked influence on the outcome of infection. On the one hand, a strong $\mathrm{CD} 4^{+} \mathrm{T}$ cell response is elicited, whereby the $\mathbf{N}$ protein represents a dominant antigen [1,36, 101]. For protection and virus elimination in the early stages of infection, both $\mathrm{CD} 4^{+}$and $\mathrm{CD} 8^{+} \mathrm{T}$ cells are important 
$[6,18,23,36,81,91,109]$. In the mouse system, non-immune $B$ cells have been described which are capable of inducing apoptosis of MHV-A59-infected cells [63]. This mechanism differs from the classical cytotoxic $\mathrm{T}$ lymphocyte function and may be triggered by cell fusion activity of the viral $S$ protein. On the other hand, if the immune response fails to eliminate the virus, a persistent infection may be established. Depending on the experimental conditions, an immune-mediated demyelination can be induced $[6,22,24,82,92,97]$.

\section{Demyelinating encephalomyelitis in rats}

Infection of several inbred rat strains with MHV-JHM results in a demyelinating CNS disease $[86,99]$. In Lewis rats, following intracerebral infection with MHV-JHM different forms of encephalomyelitis were observed. The acute encephalomyelitis (AE) develops within a short incubation time and leads rapidly to the death of the animal. The lesions are located mainly in the grey matter of the CNS. In contrast, the subacute demyelinating encephalomyelits (SDE) is a paralytic disease, which develops after an incubation time of several weeks to months and is based on a persistent infection $[61,62,110]$. Inflammatory demyelinating lesions are restricted to the cerebral white matter including the optic chiasm, brain stem and spinal cord. The disease develops after an incubation time of several weeks to months and in a number of cases relapse occurs [102].

Lewis rats and BN rats react very differently to infection with MHV-JHM [99]. Lewis rats are highly susceptible and display a strong inflammatory response in the CNS driven by $\mathrm{CD} 4^{+} \mathrm{T}$ cells. BN rats are quite resistant to MHV-JHM infection and react with a strong intrathecal antibody response $[17,18,77]$. The virus remains restricted to the periventricular regions, whereby a heavy infiltration of virus-specific antibody-secreting plasma cells occurs in the brain parenchyma.

In Lewis rats, macrophages and $\mathrm{CD4}^{+} \mathrm{T}$ cells are the major cell type in the infiltrates $[18,110]$. The cytokines released by these infiltrates may contribute to the up-regulation of major histocompatibility complex (MHC) class II antigens including microglia cells and astrocytes [80]. Results from in vitro studies have indicated that interferon (IFN)- $\gamma$ induces MHC class II expression in astrocytes, which are then capable of functioning as antigen-presenting cells [25, 78]. Furthermore, MHV-JHM virions have the capacity to elicit an up-regulation of $\mathrm{MHC}$ class II in astrocyte cultures [54]. This effect is rat strain dependent; astrocytes derived from BN rats do not display a virus-dependent up-regulation of $\mathrm{MHC}$ class II expression [55, 78]. Astrocytes can prime $\mathrm{CD}^{+} \mathrm{T}$ cells and can perpetuate $\mathrm{CD} 4^{+} \mathrm{T}$ cell functions [79]. However, in vivo the priming and proliferation of antigen-specific CD4 ${ }^{+} \mathrm{T}$ lymphocytes occurs probably in cervical lymph nodes outside the CNS. The T lymphocytes which home to the infected areas of the CNS are unresponsive to proliferation signals, but continue to produce cytokines and function as effector cells [30,79]. Therefore, it is conceivable that it is the role of activated astrocytes or microglia to mitigate the inflammatory response within the CNS. Most of the inflammatory $\mathrm{T}$ cells in older lesions are eliminated by apoptosis.

The influence of immunity on the outcome of infection was investigated by employing for immunisation recombinant vaccinia viruses, which express structural proteins of MHV-JHM. Protective immunity was induced against MHV-JHM if the challenge infection of rats was performed within 7 days following vaccination against $S$ 
protein [23]. As shown by depletion experiments, the protective effect depends on the presence of $\mathrm{S}$ protein-specific $\mathrm{CD}^{+} \mathrm{T}$ cells. However, a subclinical and protracted course of disease associated with a persistent infection was induced if the MHV-JHM challenge was performed 3 weeks after vaccination [24]. Employing this immunisation schedule, the $\mathrm{CD} 8^{+} \mathrm{T}$ cells appear to be of less importance.

It is conceivable that the presence of antiviral antibodies shields the neurons against a cytolytic virus infection and thus prevents lethal disease [49]. The conclusion that the humoral immune response may modulate the disease is supported by data from immune-histological analysis of rats displaying inflammatory demyelinating lesions [110]. Within the lesions, binding of antiviral antibodies, complement C3 and an increased amount of $\mathrm{B}$ cells are detectable, whereas the amount of $\mathrm{S}$ protein expressed is drastically reduced in comparison to the nucleocapsid protein. As shown by tissue culture experiments with measles virus-infected cells, during persistent infection in the presence of antibodies viral glycoproteins disappear from the cell surface and their expression can be down-regulated. This mechanism of antigenic modulation may help the virus escape from immmune surveillance [64].

Most fascinating was the finding that, during SDE, lymphocytes are sensitised against myelin basic protein (MBP) [98]. To test the pathogenetic potential of these cells, such lymphocytes were restimulated in vitro to enhance their number and then transferred to healthy syngeneic rats. These animals developed inflammatory lesions and clinical signs characteristic of experimental allergic encephalitis (EAE). It is noteworthy that no autoimmune response was observed in BN rats (a strain relatively resistant to induction of $\mathrm{EAE}$ and other autoimmune diseases [99]). These results support the hypothesis that autoimmunity specific for brain antigens can be triggered by a virus infection and have implications for pathogenesis.

\section{Coronavirus-induced demyelination in mice}

The susceptibility of neuronal cells and macrophages is a key element in determining the outcome of infection and may involve only one single dominant gene. By contrast, the development of chronic MHV-induced CNS disease is probably under the control of several genes [38]. A chronic demyelinating encephalomyelitis was observed in a few mice that survived the acute disease $[90,103]$. Whereas demyelination during the acute stage might be a direct consequence of a cytolytic infection affecting oligodendrocytes, astrocytes are the predominant cells that maintain the virus as a smoldering persistent infection throughout the chronic stage [92].

Some evidence has been obtained that MHV-JHM also triggers also autoimmune responses in mice. However, it is not known whether this phenomenon plays a pathogenic role leading to inflammatory demyelination. In MHV-JHM-infected BALB/c mice, the frequency of self-reactive $T$ cells was significantly elevated [40]. In this context, it is interesting that a murine coronavirus infection strongly influenced the pathology of an autoimmune relapsing encephalomyelitis in a mouse model [12]. In PL/J mice, EAE was elicited by transfer of MBP-specific lymph node cells. Only mice containing antibodies against MHV displayed large demyelinating lesions in the spinal cord. In addition, MHV-JHM induces a biphasic retinal disease in BALB/c mice [28]. In the early phase, the virus induces a retinal vasculitis. Later, when both viral particles and inflammatory cells are no longer detectable, these animals suf- 
fer from a degeneration of the retina associated with the presence of autoantibodies against retina and retinal pigment epithelial cells.

The major factor leading to primary demyelination and inflammation appears to be provoked by the antiviral immune response. A persistent virus infection and demyelination can be induced if $\mathrm{C} 57 \mathrm{~B} 1 / 6$ mice that are nursed by already immune mothers are infected [74]. This chronic disease may involve humoral antibodies, which prevent virus spread and damage of neurons during the acute phase. A similar modulation of the disease was observed after infection of mice infused with mAb against the $S$ protein $[2,92]$.

The pathology of virus-induced CNS infections depends on changes caused directly by the virus and the effects mediated by proinflammatory cytokines $[37,108]$. During the acute stage, the infection of MHV-JHM results in an increase of MHC class I expression on oligodendrocytes and astrocytes [93, 94]. This induction of MHC class I expression in astrocytes is dependent on the virus strain employed for infection [26]. In addition, a virus-mediated induction of IL-6 was demonstrated on endothelial cells and astrocytes [35]. These virus-specific immune modulatory effects are thought to involve soluble factors released from brain cells. Furthermore, besides neural cells, infiltrating monocytes and macrophages are a target for infection. Surviving the acute disease depends strongly on an efficient clearance of virus involving both $\mathrm{CD}^{+}$and $\mathrm{CD}^{+} \mathrm{T}$ lymphocytes, which act through the release of cytokines $[1,108]$. At the time of clearance, an increase of mRNA for IL-1 $\alpha$, IL-1 $\beta$, IL-6, tumor necrosis factor (TNF)- $\alpha$ and IFN- $\gamma$ was demonstrated [70]. In irradiated mice, the clearance of virus from the CNS is severely impaired. However, although the amount of infectious virus is significantly enhanced, demyelination is abrogated. Passive transfer of splenocytes from immune animals again resulted in inflammatory demyelination. Virus-specific Thy- $1^{+}$cells are, therefore, considered to be of central importance in mediating demyelination $[22,82,97]$.

\section{Common pathogenic aspects of coronavirus-induced demyelination, EAE and MS}

The process of demyelination, the involvement of autoimmunity and the clinical course of experimental coronavirus infections emulate some aspects of MS. EAE is investigated as the classical model to illustrate the involvement of autoimmunity in CNS diseases $[46,69]$. To induce EAE, animals are immunised with mixtures of MBP or myelin extracts with adjuvants. The essential pathogenic element consists of $\mathrm{CD}^{+} \mathrm{T}$ cells sensitised against "encephalitogenic" epitopes of MBP. Passive transfer of activated MBP-specific T cell lines also results in EAE. However, the lesions associated with this type of EAE model only consist of perivascular infiltrations of T cells and monocytes, whereas inflammatory demyelination is a hallmark of MS. To emulate such pathological changes, a number of experimental designs were evaluated.

One of the most successful modifications of the EAE model was achieved by a combined transfer of $\mathrm{T}$ cells specific for brain antigens and antibodies against surface proteins on oligodendrocytes or myelin. The intensity of inflammation and the degree of demyelination depend on the balance between encephalitogenic $T$ cells and antibodies. The neuropathological changes observed in these EAE models and in coronavirus-induced demyelinating disease are similar to demyelinating lesions associated with MS. In both systems a spectrum of lesions can be analysed, which represent different stages of plaque development. The pathogenic mechanism driving 
the different types of lesions appear to vary even within the same rat. In general, a persisting virus infection may provide a first antigen stimulus and disturb the balance of the immune system [111]. Viruses that replicate in neural tissue can incorporate host material, including myelin proteins, and thus provoke a normally irrelevant immune response [76]. Furthermore, epitopes of the virus may cross-react with potential neuroantigens, thus provoking autoimmunity by molecular mimicry [64]. Many direct or indirect disturbances of oligodendrocyte functions can impair myelin production, expose new antigens and progress to phases of increasing pathology. Oligodendrocytes are sensitive to exposure to TNF or IL-1 [57]. Other factors are released by activated macrophages such as nitric oxide or proteases. Finally, oligodendrocytes are sensitive to $\mathbf{C}^{\prime}$ or $\mathbf{C}^{\prime}$-mediated antibody reactions. Therefore, demyelination may also be the consequence of an "innocent bystander" effect related to an antiviral immune response.

Astrocytes are coupled through gap junctions to oligodendrocytes and secrete trophic factors. In addition, the viability of oligodendrocytes depends on the integrity of the associated axons. Furthermore, the immunomodulatory functions of astrocytes, microglia and endothelial cells can be affected by a viral infection. In particular, the virus-induced up-regulation of $\mathrm{MHC}$ or of cytokines can be implicated in the disruption of immune regulation. An immunopathological process may, thus, prevail even when the eliciting infectious agent has already been eliminated.

Despite the fascinating observations in such model systems, a direct etiological involvement of coronavirus infections in MS remains unlikely. The reports on coronaviruses isolated from CNS tissue of MS patients using mice or murine cell cultures are debatable [3]. The risk of a hidden murine coronavirus infection during prolonged passages is obvious. On the other hand, there are reports of coronavirus RNA or protein being detected in brain tissue in some MS cases [59, 88]. Furthermore, murine coronaviruses can induce encephalomyelitis in primates $[4,60]$. There have been numerous attempts to incriminate viruses as an agent which triggers MS. No epidemiological evidence indicates that coronaviruses are involved in this disease.

\section{Dysfunctions of the immune system caused by murine coronavirus infections}

A number of low-virulent MHV viruses have been isolated from mouse colonies, which display a highly variable tropism for macrophages and $\mathrm{T}$ or $\mathrm{B}$ cell lineages [5]. Natural MHV infections can impair the function of splenic cells or influence the release of immunomodulatory neurotransmitters $[5,41,83,84]$. Oral infection of $\mathrm{BALB} / \mathrm{cByJ}$ mice with MHV-JHM resulted in a transient but marked depression of T cell functions $[9,15]$. Within the first weeks of infection, the spleen cell response to polyclonal stimuli was decreased. On the other hand, spleen cells from mice infected with MHV-JHM proliferated spontaneously and produced elevated levels of IL-2 and IL-3. This spontaneous lymphokine production was measured at a time point when infectious virus had already been eliminated [39]. Moreover, the frequency of self-reactive $T$ cells was significantly elevated [40]. Following intranasal infection of BALB/c mice with MHV-A59, a transient acute phase was observed accompanied by a markedly decreased number of cells in lymphoid organs [11]. Later, when infectious virus was no longer detectable, these mice had an impaired ability to reject skin grafts. This long-term dysfunction of $T$ cells was not detectable by in vitro assays. MHVA59 does not infect $T$ or B cells. Therefore, it is conceivable that this dysfunction 
is caused by an impairment of accessory cell functions induced during the phase of acute infection.

\section{Immune cell tropism of $M H V-3$}

This murine coronavirus displays a broad spectrum of organ tropisms and can affect liver, lymphoid organs and the CNS $[47,48,100]$. The outcome of disease strongly depends on the genetic background, the route of infection and the MHV-3 biotype. $\mathrm{A} / \mathrm{J}$ mice are resistant to intraperitoneal infection, the virus being cleared within 7 days. C57BL/6 mice by contrast die within a few days post infection (p.i.) from an acute hepatitis. This genetic restriction is based on the interaction between the virus, macrophages and lymphoid cells. The lymphoid organs of animals with acute disease are severely affected. The virus induces a lytic infection of cells belonging to the $B$ cell lineage in spleen and bone marrow, which correlates with the pathogenicity of MHV-3 $[33,44]$. In addition, the splenic and thymic $T$ cell population is depleted. In these cells, a lytic viral infection is maintained through contact with stromal cells of the thymus [43].

A completely different outcome of infection was observed, when F1 hybrids derived from cross-breeding between those strains; (C57B1/6xA/J) F1 were employed [34]. These "semi-susceptible" animals are resistant to acute disease, but develop chronic diseases based on persistent infections, which can be associated with immunosuppression. Major signs consist of a wasting syndrome, hind limb paralysis and incoordination. These mice occasionally die within 3 months. Similar manifestations of chronic disease are also inducible by $\mathrm{MHV}-3$ infection of $\mathrm{C} 3 \mathrm{H}, \mathrm{AKR}$ or A2G mice.

The chronic disease is under the control of several $\mathrm{H}$-2-linked genes, which influence the degree of hepatic damage. The acute phase depends on another gene complex. The development of neurological disease depends on the level of virus replication involving meningeal cells, ependymal cells and neurons [13,95]. Although antibodies against MHV-3 are continuously detectable, a strong impairment of both primary and secondary antibody responses occurs. Furthermore, the number of thymocytes, splenic cells and macrophages decreases significantly. The number of spleen cells decreases already within 2 days p.i. and remains low for up to 3 months. Infectious virus can be isolated from different organs of chronically infected mice. The major targets are mature B cells and thymic stromal cells. Viruses isolated from CNS tissue are less pathogenic and have lost the tropism for thymocytes [45]. It is noteworthy that neurological signs develop at a time when the spleen cellularity and number of peritoneal macrophages have reached normal levels. The paralysis is thought to result from an immune-mediated lysis of infected neural cells [34]. As a consequence of the $T$ and $B$ cell depletion during the acute phase, the elimination of infectious virus may be inefficient and, thus, establishment of a persistent infection could be promoted.

\section{MHV-3-induced coagulopathies}

Macrophage function determines to a significant extent the outcome of infections with MHV-3. The restriction of MHV-3 replication is strongly associated with macrophage activation by IFN- $\gamma$ [56]. Furthermore, the activation of the blood coagulation system 
by infection with MHV-3 is a major pathogenic mechanism related to susceptibility and resistance [50]. Activation of the coagulation system can result in disseminated intravascular deposition of fibrin and, thus, lead to severe liver damage. A low basal procoagulant activity (PCA), a prothrombinase, is an intrinsic property of lymphoreticular cells. This enzymatic activity can be up-regulated by lipopolysaccharides, immune complexes or lectins. Monocytes and macrophages play a pivotal role in the induction of the PCA response.

The manner in which infection of macrophages by MHV-3 stimulates PCA is strictly dependent on the genetic background: high activity is induced in fully susceptible $\mathrm{BALB} / \mathrm{c}$ mice, moderate responses are measurable in $\mathrm{C} 3 \mathrm{H} / \mathrm{St}$ mice and no PCA activity occurs in the fully resistant $\mathrm{A} / \mathrm{J}$ strain. The PCA response develops within $1-1.5 \mathrm{~h}$ p.i., before the virus replicates. Infusion of infected BALB/c mice with an $\mathrm{mAb}$ that neutralises PCA activity has a protective effect and limited hepatic necrosis [51]. Therefore, the mechanism by which macrophages contribute to genetic restriction is via induction of the blood coagulation cascade by the virus and is not directly dependent on the virus replication. In addition, MHV-3 infection of macrophages elicits the production of TNF, leukotriene B4 and IL-1. These mediators may in turn elicit the expression of PCA in endothelial cells.

The induction of PCA in macrophages is not possible without $\mathrm{T}$ cell cooperation. $\mathrm{T}$ lymphocytes from resistant, immunised $\mathrm{A} / \mathrm{J}$ mice are capable of inhibiting expression of $\mathrm{PCA}$ in susceptible, $\mathrm{H}-2$-compatible recombinant mice. A virus-specific $\mathrm{CD}^{+}$ Th1 line has been established, which blocks the induction of PCA in macrophages [7]. Furthermore, this $T$ cell line is capable of conferring resistance to otherwise susceptible mice.

Results from several studies imply that IFN play a central role in susceptibility or resistance [56]. These cytokines display both antiviral and immunomodulatory activities. A major mechanism mediating an antiviral effect is elicited through 25 adenylate synthetase, which activates RNase $\mathrm{L}$. This endoribonuclease activity can impair the synthesis of viral RNA by degradation of single-stranded RNA. Compounds that stimulate $R$ Nase $L$ interfere with virus replication in macrophages [21]. However, MHV-3-induced PCA activity is not diminished and, thus, these substances did not prevent necrotic hepatitis. The beneficial role of IFN- $\gamma$ appears to operate through stimulation of the Th1 lymphocyte response and may not be a consequence of its antiviral effect.

\section{Conclusions and comments}

A number of coronavirus-induced disease processes are driven or accompanied by immunopathological mechanisms. Of major clinical importance is feline infectious peritonitis, which is a management problem in catteries. This antibody- and $\mathrm{C}^{\prime}$-mediated disease process displays interesting mechanistic parallels to important virus diseases of human, involving haemorrhagic shock syndromes and damage to the lymphoreticular system $[37,53]$.

Murine coronavirus infections do not appear to be of clinical importance. However, these viruses provide interesting experimental models by emulating complex disease processes and may represent as-yet-unrecognized threats or underestimated problems in biomedical studies. Infections with MHV strains affect about $60-80 \%$ of mouse colonies and are often not recognised because of their tendency to induce 
subclinical and inapparent infections. Therefore, the long-term effects of such infections on immune functions and the neuroendocrine system can severely impair the reliability of results of experiments employing mice and rats. In particular, studies with genetically manipulated animals may be invalidated if such colonies harbour an unrecognized MHV infection.

Murine coronavirus infections of rodents have been developed as versatile models for virus persistence, chronic infections and demyelination $[8,16,100]$. The results have influenced experiments with a number of other systems, such as measles virus, Sindbis virus, SFV and Theilervirus $[52,58,75]$.

The concepts derived from these studies may help to understand the pathogenesis of demyelination in EAE and MS [25, 46, 78, 111]. The CNS is no longer considered as a strictly "immunoprivileged" organ, because activated $\mathrm{T}$ cells can pass through the endothelial blood-brain barrier irrespective of their antigenic specificity. Coronavirus infections can induce dysfunctions of the immune system and trigger autoimmune reactions. Autoimmune $\mathrm{T}$ cell populations exist in the healthy organism and are not inevitably anergic or silenced. MBP is not the only encephalitogenic neuroantigen: depending on the genetic and immunological context, other molecules, e.g. proteolipid protein or a virus protein, can drive chronic demyelination. Brain cells such as cerebral endothelial cells, astrocytes or microglia can function as antigen-presenting cells involved in modulation of the immune response within the CNS. Coronaviruses have the capacity to influence these regulatory circuits.

Despite the strong reluctance to associate coronaviruses with MS, it remains an open question as to whether coronaviruses can enter the human CNS irrespective of pathological consequences. The hypothesis that virus infections may influence the clinical course of MS could be investigated in such model systems.

Acknowledgements. The author acknowledges financial support from the Deutsche Forschungsgemeinschaft and Hertie Stiftung.

\section{References}

1. Bergmann C, McMillan M, Stohlman S (1993) Characterization of the Ld-restricted cytotoxic Tlymphocyte epitope in the mouse hepatitis virus nucleocapsid protein. J Virol 67:7041

2. Buchmeier MJ, Lewicki HA, Talbot PJ, Knobler, RL (1984) Murine hepatitis virus-4 (strain JHM)induced neurologic disease is modulated in vivo by monoclonal antibody. Virology 132:261

3. Burks JS, DeVald BL, Jankovsky LD, Gerdes JC (1980) Two coronaviruses isolated from central nervous system tissue of two multiple sclerosis patients. Science 209:933

4. Cabirac GF, Soike KF, Zhang JY, Hoel K, Butunoi C, Cai G-Y, Johnson S, Murray S (1994) Entry of coronavirus into primate CNS following peripheral inoculation. Microb Pathog 16:349

5. Caseboldt DB, Spalding DM, Shoeb TR, Lindsey JR (1987) Suppression of immune response induction in Peyer's patch lymphoid cells from mice infected with mouse hepatitis virus. Cell Immunol 109:97

6. Castro R, Evans D, Jaszewski A, Perlman S (1994) Coronavirus-induced demyelination occurs in the presence of virus-specific cytotoxic $T$ cells. Virology 200:733

7. Chung S, Gorczynski R, Cruz B, Fingerote R, Skamene E, Perlman S, Leibowitz J, Fung L, Flowers M, Levy G (1994) A Th1 cell line (3E9.1) from resistant A/J mice inhibits induction of macrophage procoagulant activity in vitro and protects against MHV-3 mortality in vivo. Immunology 83:353

8. Compton SR, Barthold, SW, Smith AL (1993) The cellular and molecular pathogenesis of coronaviruses. Lab Anim Sci 43:15 
9. Cook MJ, Munshi HG, Perlman RL, Chambers DA (1992) Mouse hepatitis virus infection suppresses modulation of mouse spleen T-cell activation. Immunology 75:542

10. Corapi WV, Olsen CW, Scott FW (1992) Monoclonal antibody analysis of neutralization and antibody-dependent enhancement of feline infectious peritonitis virus. J Virol 66:6695

11. Cray C, Mateo MO, Altman NH (1993) In vitro and long-term in vivo immune dysfunction after infection of BALB/c mice with mouse hepatitis virus strain A59. Lab Anim Sci 43:169

12. Cross AH, McCarron R, McFarlin DE, Raine CS (1987) Adoptively transferred acute and chronic relapsing autoimmune encephalomyelitis in the PL/J mouse and observations on altered pathology by intercurrent virus infection. Lab Invest 57:499

13. Decimo D, Boespflug O, Meunier RM, Hadchouel M, Tardieu M (1993) Genetic restriction of murine hepatitis virus type 3 expression in liver and brain: comparative study in BALB/c and $\mathrm{C} 3 \mathrm{H}$ mice by immunochemistry and hybridization in situ. Arch Virol 130:269

14. Delmas B, Gelfi J, L'Haridon R, Vogel LK, Sjostrom H, Noren O, Laude H (1992) Aminopeptidase $\mathrm{N}$ is a major receptor for the entero-pathogenic coronavirus TGEV. Nature 357:417

15. De Souza MS, Smith AL, Bottomly K (1991) Infection of BALB/cByJ mice with the JHM strain of mouse hepatitis virus alters in vitro splenic $T$ cell proliferation and cytokine production. Lab Anim Sci 41:99

16. Dörries $R$ (1987) Neuroimmunological aspects of virus-induced demyelination in animal models. In: Aarli JA, Behan MH, Behan PO (eds) Clinical neuroimmunology. Blackwell, Oxford, pp 88-101

17. Dörries R., Watanabe $R$, Wege $H$, ter Meulen V (1987) Analysis of the intrathecal humoral immune response in Brown Norway (BN) rats, infected with the murine coronavirus JHM. J Neuroimmunol 14:305

18. Dörries, R, Schwender S, Imrich H, Harms H (1991) Population dynamics of lymphocyte subsets in the central nervous system of rats with different susceptibility to coronavirus-induced demyelinating encephalitis. Immunology 74:539

19. Dveksler GS, Dieffenbach CW, Cardellichio CB, McCuaig K, Pensiero MN, Jiang GS, Beauchemin $\mathrm{N}$, Holmes KV (1993) Several members of the mouse carcinoembryonic antigen-related glycoprotein family are functional receptors for the coronavirus mouse hepatitis virus-A59. J Virol 67:1

20. Evermann JF, McKeirnan AJ, Ott RL (1991) Perspectives on the epizootiology of feline enteric coronavirus and the pathogenesis of feline infectious peritonitis. Vet Microbiol 28:243

21. Fingerote RJ, Cruz BM, Gorczynski RM, Fung LS, Hubbell HR, Suhadolnik RJ, Levy GA (1995) A $2^{\prime}, 5^{\prime}$-oligoadenylate analogue inhibits murine hepatitis virus strain 3 (MHV-3) replication in vitro but does not reduce MHV-3-related mortality or induction of procoagulant activity in susceptible mice. J Gen Virol 76:373

22. Fleming JO, Wang FI, Trousdale MD, Hinton DR, Stohlman SA (1993) Interaction of immune and central nervous systems: contribution of anti-viral Thy $-1^{+}$cells to demyelination induced by coronavirus JHM. Reg Immunol 5:37

23. Flory E, Pfleiderer M, Stïhler A, Wege $\mathbf{H}$ (1993) Induction of protective immunity against coronavirusinduced encephalomyelitis: evidence for an important role of $\mathrm{CD}^{+} \mathrm{T}$ cells in vivo. Eur $\mathrm{J}$ Immunol 23:1757

24. Flory E, Stühler A, Barac-Latas V, Lassmann H, Wege H (1995) Coronavirus-induced encephalomyelitis: balance between protection and immune pathology depends on the immunization schedule with spike protein S. J Gen Virol 76:873

25. Fontana A, Frei K, Bodmer S, Hofer E (1987) Immune-mediated encephalitis: on the role of antigenpresenting cells in brain tissue. Immunol Rev 100:185

26. Gilmore W, Correale J, Weiner LP (1994) Coronavirus induction of class I major histocompatibility complex expression in murine astrocytes is virus strain specific. J Exp Med 180:1013

27. Hohdatsu T, Nakamura M, Ishizuka Y, Yamada H, Koyama H (1991) A study on the mechanism of antibody-dependent enhancement of feline infectious peritonitis virus infection in feline macrophages by monoclonal antibodies. Arch Virol 120:207

28. Hooks JJ, Percopo C, Wang Y, Detrick B (1993) Retina and retinal pigment epithelial cell autoantibodies are produced during murine coronavirus retinopathy. J Immunol 151:3381

29. Horzinek MC, Ederveen J, Egberink H, Jacobse-Geels HEL, Niewold T, Prins J (1986) Virion polypeptide specificitiy of immune complexes and antibodies in cats inoculated with feline infectious peritonitis virus. Am J Vet Res 47:754 
30. Imrich H, Schwender S, Hein A, Dörries R (1994) Cervical lymphoid tissue but not the central nervous system supports proliferation of virus-specific $\mathrm{T}$ lymphocytes during coronavirus-induced encephalitis in rats. J Neuroimmunol 53:73

31. Jacobse-Geels HE, Daha MR, Horzinek MC (1980) Isolation and characterization of feline C3 and evidence for the immune complex pathogenesis of feline infectious peritonitis. J Immunol 125:1606

32. Jacobse-Geels HE, Daha MR, Horzinek MC (1982) Antibody, immune complexes, and complement activity fluctuations in kittens with experimentally induced feline infectous peritonitis Am J Vet Res 43:666

33. Jolicoeur P, Lamontagne L (1989) Mouse hepatitis virus 3 pathogenicity expressed by a lytic viral infection in bone marrow $14.8^{+} \mu^{+} \mathrm{B}$ lymphocyte subpopulations. J Immunol 143:3722

34. Jolicoeur $P$, Lamontagne $L$ (1994) Impaired $T$ and B cell subpopulations involved in a chronic disease induced by mouse hepatitis virus type 3 . J Immunol 153:1318

35. Joseph J, Grun JL, Lublin FD, Knobler RL (1993) Interleukin-6 induction in vitro in mouse brain endothelial cells and astrocytes by exposure to mouse hepatitis virus (MHV-4, JHM). J Neuroimmunol 42:47

36. Körner H, Schliephake A, Winter J, Zimprich F, Lassmann H, Sedgwick J, Siddell S, Wege H (1991) Nucleocapsid or spike protein-specific $\mathrm{CD}^{+} \mathrm{T}$ lymphocytes protect against coronavirus-induced encephalomyelitis in the absence of $\mathrm{CD}^{+} \mathrm{T}$ cells. J Immunol 147:2317

37. Kurane I, Ennis FA (1994) Cytokines in dengue virus infections: role of cytokines in the pathogenesis of dengue hemorrhagic fever. Semin Virol 5:443

38. Kyuwa S, Stohlman SA (1990) Pathogenesis of a neurotropic murine coronavirus, strain JHM in the central nervous system of mice. Virology 1:273

39. Kyuwa S, Yamaguchi K, Hayami M, Hilgers J, Fujiwara K (1988) Spontaneous production of interleukin- 2 and interleukin- 3 by spleen cells from mice infected with mouse hepatitis virus type 4. J Virol 62:3506

40. Kyuwa S, Yamaguchi K, Toyoda Y, Fujiwara K (1991) Induction of self-reactive T cells after murine coronavirus infection. J Virol 65:1789

41. Kyuwa S, Cohen M, Nelson G, Tahara SM, Stohlman SA (1994) Modulation of cellular macromolecular synthesis by coronavirus: implication for pathogenesis. J Virol 68:6815

42. Lai MM, (1990) Coronavirus: organization, replication and expression of genome. Annu Rev Microbiol $44: 303$

43. Lamontagne L, Jolicoeur P (1991) Mouse hepatitis virus 3-thymic cell interactions correlating with viral pathogenicity. J Immunol 146:3152

44. Lamontagne L, Descoteaux J, Jolicoeur P (1989) Mouse hepatitis virus 3 replication in $T$ and $B$ lymphocytes correlate with viral pathogenicity. J Immunol 142:4458

45. Lamontagne L, Decarie D, Jolicoeur P (1990) Immune cell tropisms of attenuated MHV3 viruses isolated from brains of chronically infected mice. Viral Immunol 3:1

46. Lassmann H, Zimprich F, Rössler K, Vass K (1991) Inflammation in the nervous system. Basic mechanisms and immunological concepts. Rev Neurol (Paris) 147:763

47. Le Prevost C, Virelizier JL, Dupuy JM (1975) Immunopathology of mouse hepatititis virus type 3 infection. Clinical and virologic observation of a persistent infection. J Immunol 115:640

48. Leray D, Dupuy C, Dupuy JM (1982) Immunopathology of mouse hepatitis virus type 3 infection. IV. MHV3-induced immunosuppression. Clin Immunol Immunopathol 23:1457

49. Levine B, Hardwick M, Trapp B, Crawford TO, Bollinger RC, Griffin D (1991) Antibody-mediated clearance of alphavirus infection from neurons. Science 254:856

50. Levy GA, Leibowitz JL, Edgington TS (1981) Induction of monocyte procoagulant activity by murine hepatitis virus type 3 parallels disease susceptibility in mice. J Exp Med 154:1150

51. Li C, Fung LS, Chung S, Crow A, Myers-Mason N, Phillips MJ, Leibowitz JL, Cole E, Ottaway CA, Levy G (1992) Monoclonal antiprothrombinase (3D4.3) prevents mortality from murine hepatitis virus (MHV-3) infection. J Exp Med 176:689

52. Liebert UG, Linington C, ter Meulen V (1988) Induction of autoimmune reactions tomyelin basic protein in measles virus encephalitis in Lewis rats. I Neuroimmunol 17:103

53. Lund O, Hansen J, Sorensen AM, Mosekilde E, Nielsen JO, Hansen JES (1995) Increased adhesion as a mechanism of antibody-dependent and antibody-independent complement mediated enhancement of human immunodeficiency virus infection. J Virol 69:2393

54. Massa PT, Dörries R, ter Meulen V (1986). Viral particles induce Ia antigen expression on astrocytes. Nature 320:543 
55. Massa PT, Brinkmann R, ter Meulen V (1987) Inducibility of Ia antigen on astrocytes by murine coronavirus JHM is rat strain dependent. J Exp Med 166:259

56. Mello IG, Vassao RC, Pereira CA (1993) Virus specificity of the antiviral state induced by IFN- $\gamma$ correlates with resistance to MHV 3 infection. Arch Virol 132:281

57. Merill JE, (1991) Effects of interleukin-1 and tumor necrosis factor alpha on astrocytes, microglia, oligodendrocytes and glial precursors in vitro. Dev Neurosci 13:130

58. Mokhtarian F, Shi Y, Zhu PF, Grob D (1994) Immune responses, and autoimmune outcome, during virus infection of the central nervous system. Cell Immunol 157:195

59. Murray RS, Brown B, Brian D, Cabirac GF, (1992) Detection of coronavirus RNA and antigen in multiple sclerosis brain. Ann Neurol 31:525

60. Murray RS, Cai GY, Hoel K, Zhang JY, Soike KF, Cabirac GF (1992) Coronavirus infects and causes demyelination in primate central nervous system. Virology 188:274

61. Nagashima K, Wege H, Meyermann R, ter Meulen V (1978) Coronavirus induced subacute demyelinating encephalomyelitis in rats. A morphological analysis. Acta Neuropathol (Berl) 44:63

62. Nagashima K, Wege H, Meyermann R, ter Meulen V (1979) Demyelinating encephalomyelitis induced by a long-term corona virus infection in rats. Acta Neuropath (Berl) 45:205

63. Nishioka, WK, Welsh RM (1993) B cells induce apoptosis via a novel mechanism in fibroblasts infected with mouse hepatitis virus. Nat Immun 12:113

64. Oldstone, MBA, (1991) Molecular anatomy of viral persistence. J Virol 65:6381

65. Olsen CW (1993) A review of feline infectious peritonitis virus: molecular biology, immunopathogenesis, clinical aspects, and vaccination. Vet Microbiol 36:1

66. Olsen CW, Scott F (1993) Evaluation of antibody-dependent enhancement of feline infectious peritonitis virus infectivity using in situ hybridization. Microb Pathog 14:275

67. Olsen CW, Corapi WV, Ngichabe CK, Baines JD, Scott FW (1992) Monoclonal antibodies to the spike protein of feline infectious peritonitis virus mediate antibody-dependent enhancement of infection of feline macrophages J Virol 66:965

68. Olsen CW, Corapi WV, Jacobson RH, Simkins RA, Saif LJ, Scott FW (1993) Identification of antigenic sites mediating antibody-dependent enhancement of feline infectious peritonitis virus infectivity. J Gen Virol 74:745

69. Olsson T (1994) Role of cytokines in multiple sclerosis and experimental autoimmune encephalomyelitis. Eur J Neurol 1:7

70. Pearce BD, Hobbs MV, McGraw TS, Buchmeier MJ (1994) Cytokine induction during T-cellmediated clearance of mouse hepatitis virus from neurons in vivo. J Virol 68:5483

71. Pedersen NC (1988) Feline infectious peritonitis. In: Pedersen NC (ed) Feline infectious diseases. American Veterinary Publications, Santa Barbara, p45

72. Pedersen NC, Boyle JF (1980) Immunologic phenomena in the effusive form of feline infectious peritonitis Am J Vet Res 41:868

73. Pedersen NC, Boyle JF, Floyd K, Fudge A, Barker J (1981) An enteric coronavirus infection of cats and its relationship to feline infectious peritonitis. Am J Vet Res 42:368

74. Perlmann S, Schelper R, Bolger E, Ries D (1987) Late onset, symptomatic, demyelinating encephalomyelitis in mice infected with MHV-JHM in the presence of maternal antibody. Microb Pathog 2:185

75. Rodriguez M, Prayoonwiwat N, Howe C, Sanborn K (1994) Proteolipid protein gene expression in demyelination and remyelination of the central nervous system: a model for multiple sclerosis. $J$ Neuropathol Exp Neurol 53:136

76. Rott O, Herzog S, Cash E (1994) Autoimmunity caused by host cell protein-containing viruses. Med Microbiol Immunol 183:195

77. Schwender S, Imrich H, Dörries R (1991) The pathogenic role of virus-specific antibody-secreting cells in the central nervous system of rats with different susceptibility to coronavirus-induced demyelinating encephalitis. Immunology 74:533

78. Sedgwick JD, Dörries R (1991) The immune system response to viral infection of the CNS. Neurosciences 3:93

79. Sedgwick JD, Mößner R, Schwender S, ter Meulen V (1991) Major histocompatibility complexexpressing nonhematopoetic astroglial cells prime only $\mathrm{CD}^{+} \mathrm{T}$ lymphocytes: astroglial cells as perpetuators but not initiators of $\mathrm{CD}^{+} \mathrm{T}$ cell responses in the central nervous system. $\mathrm{J}$ Exp Med 173:1235 
80. Sedgwick JD, Schwender S, Imrich H, Dörries R, Butcher GW, ter Meulen V (1991) Isolation and direct characterization of resident microglial cells from the normal and inflamed central nervous system. Proc Natl Acad Sci USA 88:7438

81. Shibata S, Kyuwa S, Lee SK, Toyoda Y, Goto N (1994) Apoptosis induced in mouse hepatitis virus-infected cells by a virus-specific $\mathrm{CD} 8^{+}$cytotoxic T-lymphocyte clone. J Virol 68:7540

82. Shubin RA, Sussman MA, Fleming JO, Stohlman SA (1990) Relapsing encephalomyelitis following transfer of partial immunity to JHM virus. Microb Pathog 8:305

83. Smith AL, Bottomly K, Winograd DF (1987) Altered splenic T cell function of BALB/cByJ mice infected with mouse hepatitis virus or Sendai virus. J Immunol 138:3426

84. Smith AL, Winograd DF, De Souza MS (1991) In vitro splenic T cell responses of diverse mouse genotypes after oronasal exposure to mouse hepatitis virus, strain JHM. Lab Anim Sci 41:106

85. Snijder E, Horzinek M (1993) Toroviruses: replication, evolution and comparison with other members of coronavirus-like superfamily. J Gen Virol 74:2305

86. Sorensen O, Percy D, Dales S (1980) In vivo and in vitro models of demyelinating diseases. III. JHM virus infection of rats. Arch Neurol 37:478

87. Spaan W, Cavanagh D, Horzinek MC (1988) Coronaviruses: structure and genome expression. J Gen Virol 69:2939

88. Stewart J, Mounir S, Talbot P (1992) Human coronavirus gene expression in the brains of multiple sclerosis patients. Virology 191:502

89. Stoddart CA, Scott FW (1989) Intrinsic resistance of feline peritoneal macrophages to coronavirus infection correlates with in vivo virulence. $J$ Virol 63:436

90. Stohlman SA, Weiner LP (1981) Chronic central nervous system demyelination after JHM virus infection. Neurology 31:38

91. Stohlman SA, Bergmann CC, van der Veen RC, Hinton DR (1995) Mouse hepatitis virus-specific cytotoxic $\mathrm{T}$ lymphocytes protect from lethal infection without eliminating virus from the central nervous system. J Immunol 69:684

92. Sun N, Perlman S (1995) Spread of a neurotropic coronavirus to spinal cord white matter via neurons and astrocytes. J Virol 69:633

93. Suzumura A, Lavi E, Weiss SR, Silberberg DH (1986) Coronavirus infection induces H-2 antigen expression on oligodendrocytes and astrocytes. Science 232:991

94. Suzumura A, Lavi E, Bhat S, Murasko D, Weiss SR, Silberberg DH (1988) Induction of glial cell MHC antigen expression in neurotropic coronavinus infections. Characterization of the $\mathbf{H}$-2-inducing soluble factor elaborated by infected brain cells. J Immunol 140:2068

95. Tardieu M, Boesfiug O, Barbe T (1986) Selective tropism of neurotropic coronavirus for ependymal cells, neurons and meningeal cells. J Virol 60:574

96. Vennema H, DeGroot R, Harbour DA, Dalderup M, Gruffydd-Jones T, Horzinek MC, Spaan WJM (1990) Early death after feline infectious peritonitis challenge due to recombinant vaccinia virus immunization. J Virol 64:1407

97. Wang FI, Stohlman SA, Fleming JO (1990) Demyelination induced by murine hepatitis virus JHM strain (MHV-4) is immunologically mediated. J Neuroimmunol 30:31

98. Watanabe $\mathbf{R}$, Wege $H$, ter Meulen V (1983) Adoptive transfer of EAE-like lesions by BMP stimulated lymphocytes from rats with coronavirus-induced demyelinating encephalomyelitis. Nature 305:150

99. Watanabe $\mathbf{R}$, Wege $\mathbf{H}$, ter Meulen V (1987) Comparative analysis of coronavirus JHM-induced demyelinating encephalomyelitis in Lewis and Brown Norway rats. Lab Invest 57:375

100. Wege H, Siddell S, ter Meulen V (1982) The biology and pathogenesis of coronavinuses. Curr Top Microbiol Immunol 99:165

101. Wege H, Schliephake A, Kömer H, Flory E, Wege H (1993) An immunodominant CD4 ${ }^{+}$T cell site on the nucleocapsid protein of murine coronavirus contributes to protection against encephalomyelitis. J Gen Virol 74:1287

102. Wege $H$, Watanabe $R$, ter Meulen V (1984) Relapsing subacute demyelinating encephalomyelitis in rats in the course of coronavirus JHM infection. J Neuroimmunol 6:325

103. Weiner LP (1973) Pathogenesis of demyelination induced by a mouse hepatitis virus (JHM virus). Arch Neurol 28:298

104. Weiss RC, Scott FW (1981) Antibody-mediated enhancement of disease in feline infectious peritonitis: comparison with dengue hemorrhagic fever. Comp Immunol Microbiol Infect Dis 4:175

105. Weiss RC, Scott FW (1981) Pathogenesis of feline infectious peritonitis: nature and development of viremia. Am J Vet Res 42:382 
106. Weiss RC, Scott FW (1981) Pathogenesis of feline infectious peritonitis: pathologic changes and immunofluorescence. Am J Vet Res 42:2036

107. Weiss RC, Dodds WJ, Scott FW (1980) Disseminated intravascular coagulation in experimentally induced feline infectious peritonitis. Am $\mathrm{J}$ Vet Res 41:663

108. Wesseling SL, Griffin DE (1994) Local cytokine responses during acute and chronic viral infections of the central nervous system. Semin Virol 5:457

109. Williamson JS, Stohlman SA (1990) Effective clearance of mouse hepatitis virus from the central nervous system requires both $\mathrm{CD}^{+}$and $\mathrm{CD} 8^{+} \mathrm{T}$ cells. $\mathrm{J}$ Virol $64: 4589$

110. Zimprich F, Winter J, Wege H, Lassmann H (1991) Coronavirus induced primary demyelination: indications for the involvement of a humoral immune response. Neuropathol Appl Neurobiol 17:469

111. Zinkernagel R (1993) Immune protection vs. immunpathology vs. autoimmunity: a question of balance and of knowledge. Brain Pathol 3:115 